\title{
Designing and Implementing an Assistive Technology Lab for Postsecondary Education
}

\author{
Beth Jones ${ }^{1, *}$, Nichole Williams ${ }^{1}$ and Belinda Rudinger ${ }^{2}$ \\ 1 Department of Psychology, Counseling, and Special Education, Texas A\&M University-Commerce, \\ PO Box 3011, Commerce, TX 75429, USA; nwilliams27@leomail.tamuc.edu \\ 2 School of Education, University of Wisconsin, 2100 Main St., Stevens Point, WI 54481, USA; \\ Belinda.Rudinger@uwsp.edu \\ * Correspondence: beth.jones@tamuc.edu
}

Received: 30 November 2017; Accepted: 9 January 2018; Published: 11 January 2018

\begin{abstract}
A literature review discusses how teacher knowledge of assistive technology significantly impacts student success with assistive technology and that many teachers enter the field feeling unprepared to implement these technologies with students. This article explores one university's process in setting up an assistive technology laboratory for students to explore. Such experiential learning opportunities are vital to the success of special education educators. This paper explores how the lab is set up and the activities visitors complete to provide a foundation for those looking to develop a similar lab.
\end{abstract}

Keywords: assistive technology; teacher preparation; students with disabilities

\section{Introduction}

The U.S. Department of Education, Office of Special Education reported that 5,944,241 students ages 5-21 were provided special education services under the Individuals with Disabilities Education Act (IDEA), Part B in 2016. Individual education program (IEP) teams for each of these students must consider their need for Assistive Technology (AT) in order to access the curriculum [1]. However, for AT to be utilized appropriately and effectively, teachers must be trained it its use; research has shown that students' success using AT is due in large part to the comfort level of their teacher with the technology [2]. Furthermore, Lee and Vega found that training in AT impacted teachers' perceptions of its importance [3]. Specifically, special education teachers who had received AT training considered AT a key part of their students' daily routines, whereas the opposite was true of special education teachers without AT training. Namely, those without training did not view the AT as such an important component of their students' daily life. This means that a teacher who lacks the knowledge of or skills with AT may limit the success his/her students can have using this technology. In fact, teacher understanding and preparation related to AT is the primary predictor of their students' AT use, but even among teacher preparation programs that offer instruction in AT barely half provide hands-on access to AT devices for instructional purposes [4,5].

Due to this need for teacher preparation regarding AT, an Assistive Technology Lab was started at Texas A\&M University-Commerce (TAMUC) through a self -funded, collaborative effort. In addition to providing resources for students in teacher preparation programs, the lab allows for students with disabilities to arrange times to use devices, and the lab eventually hopes to allow access to families from the community. Given the importance of promoting teacher knowledge of AT in order to foster student success, this article will describe the lab creation process, the setup of the lab, and AT curriculum considerations. As the AT Lab at TAMUC provides learning experiences to benefit teacher preparation and serves as a possible model for future labs with similar aims, the information provided is intended to provide a frame of reference for those seeking to establish similar learning experiences. 


\section{Preparation}

The lab is a joint venture between the Department of Psychology, Counseling, and Special Education, the Center for Information Technology Excellence, and the Gee Library at TAMUC. In preparation to start the lab, the project lead visited the Assistive and Instructional Technology Lab at the University of Texas at Austin, where students can access a wide range of AT devices, and Esther's Place, a model home located at The American Federation for the Blind, which features accommodations for those with vision loss [6,7]. One common feature of both facilities is that they are arranged by authentic living spaces. It was noted that the UT Austin lab is located in their main, multi-level education building. Because the project lead wanted to capitalize on inter-departmental utilization of the lab (i.e., Department of Curriculum and Instruction, Department of Psychology, Counseling, and Special Education, and Agricultural Education), it was determined that the campus library would make a good central location for the lab. In addition, there was an existing Teacher Resource Center that the lab could be located in proximity to, there is access to the lab via an accessible elevator, and the library offers the best accessibility to families and community members.

\section{Lab Organization}

Due to space constraints, the TAMU-C AT Lab is arranged into interactive, color-coded stations. These stations run along the perimeter of the $17^{\prime} \times 25^{\prime}$ room and have brightly colored tack boards to distinguish each of them (see Figure 1). Each station features a computer, an iPad, and two chairs. Stations are focused on a specific type of disability/family of disabilities recognized by IDEA. The stations feature software/hardware (ranging from low to high-tech), apps, activities, and information on each type of disability. Additionally, all of the stations feature QR codes linked to pertinent websites, real examples of classroom application, and books/resources with further information.
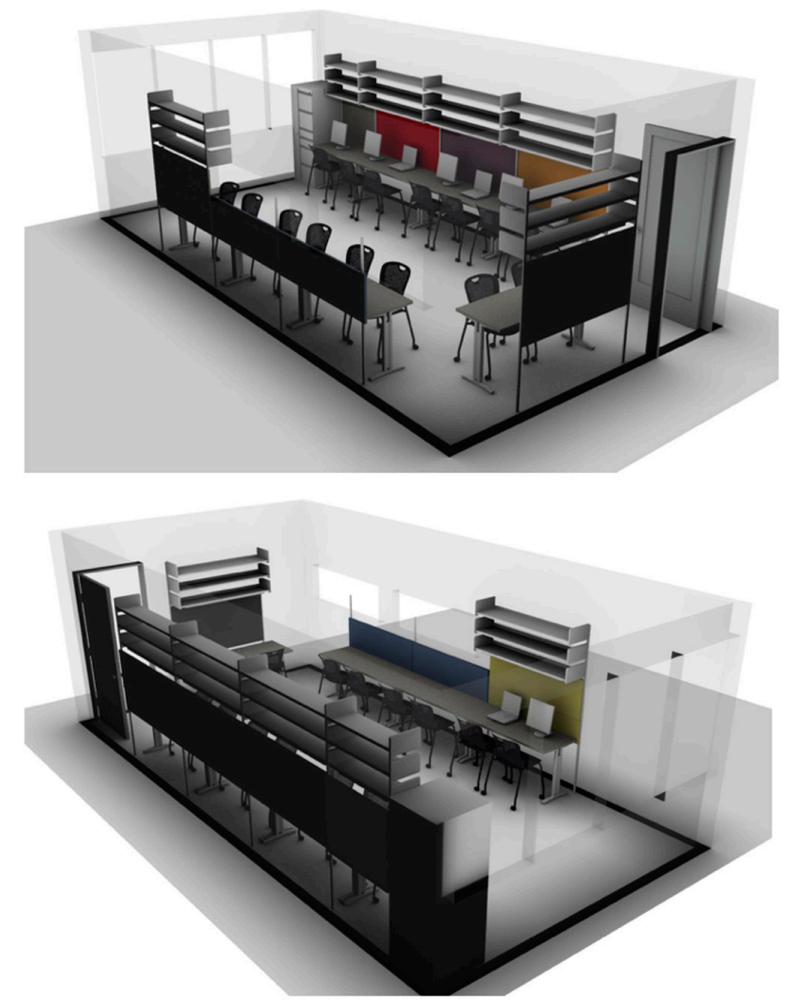

Figure 1. Pictorial representations of the Assistive Technology (AT) Lab. 
In addition to interactive stations, there is an AT timeline displayed in the lab. The events on the timeline are color-coded to correspond to the station that it most directly relates to. For example, the Sensory Impairments station is yellow and the timeline outlines the invention of the Perkins Braille Machine in 1951 with a yellow border. Also, on display are news stories featuring AT, information regarding AT and the law, and information addressing frequently asked questions about AT (i.e., What is an AT device?, how should AT be included in the IEP?).

\section{Stations}

There are a total of seven stations—six focused stations and a make and take station-in the AT Lab. Following is a description of each.

The first station is the Communication/Behavior station and it features AT that can be used to help school-aged students with speech and language impairments, autism spectrum disorders (ASD), and emotional/behavioral disorders (EBD). In this station, students can interact with Boardmaker software (Mayer-Johnson a Tobii Dynavox Company: Danderyd, Sweden) which allows for teachers to construct social stories or visual schedules. In addition, apps on the iPad include ones for communication (Proloquo2Go), social story creation (Social Stories, Model Me Going Places), behavior modification (Class Dojo, Traffic Light!), and more.

As part of the Communication/Behavior station, real-world classroom application examples are provided. These include materials used in the Teaching, Expanding Appreciating, Collaborating, Cooperating, and Holistic (TEACCH) Method [8]. The TEACCH method is designed to provide structure to students with autism using physical organization, scheduling, and teaching methods [9]. Specific examples of this research-based, structured teaching method include a model for student independent work space organization, visual schedules, and a wants and needs folder. Students use these for organization, easing transitions, or for communication. For example, on a visual schedule, a student has images depicting tasks to complete that are in order of when they should becompleted. As each task is finished, a student can move the task from the "To do" side to the "Finished" side.

The next station is the Academics station. This station addresses specific learning disabilities (SLD) and intellectual disability (ID). Software in this station includes Kurzweil Software 3000 (Kurzweil Education, Inc.; Edwardsville, IL, USA), which reads texts aloud, Live Scribe pens (LiveScribe, Inc.; Oakland, CA, USA) to assist in note-taking, and Kidspiration 3.0 software (Inspiration Software, Inc.; Portland, OR, USA) that creates visual maps to aid in understanding concepts. Apps featured in this section include apps to assist in reading development, such as One Minute Reader; apps for math development, such as Math Drills; and apps for note taking, such as Note Taker HD. Also, in this station are devices, such as pencil holders and talking calculators, which could help children struggling with writing or computation.

Another station is the Sensory Impairments station. In this station, AT for school-aged students who are Deaf, have an auditory impairment (AI), or have visual impairment (VI) are presented. Features of this station are large font keyboards, a Comtek AT-216 wireless auditory device (B \& H; New York, NY, USA) for better hearing across a distance, a monocular, Ruby hand-held video magnifiers (Freedom Scientific; St. Petersburg, FL, USA), dark lined paper for those with a visual impairment, and more. Students can also experiment with ZoomText (AI Squared, Christal Vision; San Antonio, TX, USA), Jaws Pro (Freedom Scientific; St. Petersburg, FL, USA), and MAGic v13.0 software (Freedom Scientific; St. Petersburg, FL, USA), each of which perform a variety of services, such as enlarging text on the computer, changing contrast to make the font easier to read, and reading text aloud. Apps featured at this station are geared to those with VI, such as Color Name Identifier. Students can interact with a children's book written in braille and review examples of proper contrasts to use when creating documents or websites for school-aged students with VI. As a supplement to this station, an additional station features an ONYX HD video magnifier (Freedom Scientific; St. Petersburg, FL, USA), which allows for magnification of documents or magnification of the classroom board from across the room, and the SARA CE scanner and reader (Freedom Scientific; St. Petersburg, FL, USA), which scans documents and reads them to those with VI or reading disabilities. Across the room from 
this supplemental station is a smartboard students can incorporate in many ways to help school-aged students with any number of disabilities explored by the lab. This is directly used by this station when students use the ONYX HD to view material on the board from across the room and in an enlarged format on its screen.

The next station focuses on those with physical disabilities. The Physical Impairments station features AT that aids those with impairments such as multiple sclerosis, cerebral palsy, traumatic brain injury, limb deficiencies, and more. Additionally, this station includes those with other health impairments (OHI), such as ADHD, asthma, cancer, etc. This station allows for students to experience touch free keyboards, the n-Abler (Pretorian Technologies, Ltd.; Lincolnshire, UK), and a Track-It mouse (Pretorian Technologies, Ltd.; Lincolnshire, UK), which are designed to be easier to operate for those with physical impairments, and Dragon Naturally Speaking dictation software (Nuance Communications, Inc.; Burlington, MA, USA).

The last station for students is the daily living station. This station features independent living aids, including a flashing doorbell for those with hearing loss, touch dots and braille labels for those with VI, a hair dryer stand for those with physical impairments, and other examples of AT that can be used in the home. As part of exploring the home living area, students are encouraged to debate the different accommodations people would need and discuss which devices are most universally designed (i.e., measuring cups with varying designs). Such debates occur between students in pairs or small groups at the individual stations and are discussed again as a large group at the conclusion of lab activities. Many of the items at this station were acquired by the project lead who toured an on-campus student housing facility that was scheduled to be demolished and selected appropriate items (i.e., an oven panel for displaying touch dots). The show and tell items were then mounted on painted back boards for display.

\section{Lab Activities}

As aligning the undergraduate and/or graduate curriculum to support a course in AT takes planning and time, currently the lab is being utilized to aide in the embedding of AT information in existing courses. TAMUC students visit the lab at a professor's request or come to the lab with a class. This is done as a requirement for a course or as part of a program seminar held each semester for education students. While not all students who visit plan to become special educators, the importance of AT is emphasized. Additionally, for those not planning on becoming special educators, additional attention is paid to making connections for uses in general education classrooms. A graduate assistant and/or special education faculty member guides the students through the activities. Additionally, the activities are tailored to fit the needs of the group to promote multiple visits to the lab. By allowing for students to interact in multiple ways with the AT, students can gain more knowledge and comfort with it. For those who only attend once, the activities are designed to provide a wide exposure to establish a stronger knowledge base.

A scavenger hunt (see Figure 2) was designed specifically to aid students in exploring all that the lab has to offer. This scavenger hunt allows students, partners, or groups a structured way to view the lab. Students who have completed the scavenger hunt are encouraged to share what they have learned, leave information on resources they know of that were not featured in the lab, or to make a permanent product such as a social story to take with them. Other activities have included an activity requiring students to identify an AT that would be helpful for a student given a specific need (see Figure 3) and students bringing case studies from their classes into the lab to develop a better understanding of what resources are available to help their specific case. The students are also encouraged to read about AT in the news and to bring in stories they find about AT to help keep this news current. Lastly, because research suggests that interaction with people with disabilities is likely vital to changing attitudes or behavior, whenever possible, we attempt to expose TAMU-C students to individuals who actually benefit from some of the technologies [10]. 


\section{Assistive Technology Lab Scavenger Hunt}

Use the clues and resources posted around the lab to answer the following questions:

1. What are the 13 disability categories covered under the Individuals with Disabilities Education Act (IDEA)?

2. Explore the lab and the IRIS Module on AT (QR Code Scan) to answer the following questions:

a. What is an AT device/service?

b. How can IEP teams ensure they are considering AT needs/addressing AT on the IEP (Use the Incorporating AT Into the IEP QR Code Scan)?

c. What is the difference between no tech, low tech, and high tech AT?

3. Refer to the AT Timeline and identify milestones in the development of AT for individuals with various needs.

4. What are the major provisions of the law regarding AT?

5. Compare and contrast Universal Design for Learning (UDL) and AT.

6. What skills can the Teach Town and Boardmaker programs be used for?

7. Find the Kidspiration software at the Academics station. What can this be used for?

8. Locate the ONYX, SARA CE, RUBY, and talking calculator. What are the features of these machines? What would advantages and disadvantages of each?

9. Use clues in the Tips to make Print More Readable QR Code Scan to identify the stations displaying color contrast schemes recommended for individuals with visual impairments.

10. Using any iPad in the lab:

a. Open Safari and navigate to www.learningally.org. Browse the library of audio books. Who could benefit from this resource?

b. Access the iPad app 'Learning Ally Audio' and open a title.

11. Explore the Daily Living Station/QR Code for Household Products by MaxiAids and find one adaption that you had not previously thought about and describe how it can be useful. (Note: Don't miss the wireless flashing doorbell mounted on the "door" by the physical impairments station and that each station has lighting under the shelves as is needed in kitchens for people with visual impairments.)

Figure 2. Assistive Technology Lab Scavenger Hunt.

\subsection{A Framework for Assistive Technology Curriculum}

Faculty interested in infusing AT into their higher education curriculum on a grander scale should consult the established literature [11]. Regardless of where your program is functioning in terms of AT infusion into the curriculum, it is important to deliver content in relation to the components of the SETT (Student, Environments, Tasks, and Tools) Framework [12]. "The SETT Framework was developed to help (educational) teams gather and organize information so that they can make appropriate assistive technology decisions during all phases of assistive technology service delivery, from consideration through evaluation of effectiveness" [13]. Specifically, this framework helps to ensure that recommended AT is a good fit for students, their environment, and the specific tasks they need to be able to complete. In addition, information on AT should discuss the continuum of options (no tech, low tech, and high tech), with emphasis being placed on the idea that the highest tech options are not always needed or most appropriate. Finally, the importance of creating accessible, or universally designed, materials is a crucial component of content delivery. Without a guiding 
framework including these essential elements, AT recommendations may be based on what is popular, preferred by the teacher, novel, or what is conveniently available rather than what is the best fit for the specific student and situation.

\begin{tabular}{|c|c|c|c|}
\hline $\begin{array}{l}\text { Your student has a speech } \\
\text { impairment and... }\end{array}$ & & & \\
\hline \multicolumn{4}{|l|}{$\begin{array}{l}\text { they cannot speak, but need to } \\
\text { communicate on the go. }\end{array}$} \\
\hline & $\begin{array}{l}\text { What tool(s) could they/you } \\
\text { use? }\end{array}$ & What does this tool do? & $\begin{array}{l}\text { Can this be useful for } \\
\text { somebody with a different } \\
\text { disability? If so, what kind? }\end{array}$ \\
\hline \multicolumn{4}{|l|}{$\begin{array}{l}\text { Your student recieves services } \\
\text { due to emotional disturbances } \\
\text { and... }\end{array}$} \\
\hline \multicolumn{4}{|l|}{$\begin{array}{l}\text { struggles with transitions. You } \\
\text { decide to make a visual } \\
\text { schedule. }\end{array}$} \\
\hline $\begin{array}{l}\text { doesn't know how to } \\
\text { appropriately behave when } \\
\text { they are working in a group. } \\
\text { You need a way to show them } \\
\text { the appropriate behavior. }\end{array}$ & & & \\
\hline \multicolumn{4}{|l|}{$\begin{array}{l}\text { Your student has dyslexia } \\
\text { and... }\end{array}$} \\
\hline \multicolumn{4}{|l|}{$\begin{array}{l}\text { they need to be able to hear } \\
\text { what is written on their paper in } \\
\text { order to best understand it. }\end{array}$} \\
\hline \multicolumn{4}{|l|}{$\begin{array}{l}\text { struggles to read the online } \\
\text { research article they are } \\
\text { assigned to present on. }\end{array}$} \\
\hline & $\begin{array}{l}\text { What tool(s) could they/you } \\
\text { use? }\end{array}$ & What does this tool do? & $\begin{array}{l}\text { Can this be useful for } \\
\text { somebody with a different } \\
\text { disability? If so, what kind? }\end{array}$ \\
\hline \multicolumn{4}{|l|}{$\begin{array}{l}\text { Your student struggles in math } \\
\text { and reading.... }\end{array}$} \\
\hline \multicolumn{4}{|l|}{$\begin{array}{l}\text { what could help them with } \\
\text { math? }\end{array}$} \\
\hline \multicolumn{4}{|l|}{$\begin{array}{l}\text { what could help them with } \\
\text { reading? }\end{array}$} \\
\hline $\begin{array}{l}\text { What could help them make } \\
\text { connections with visuals? }\end{array}$ & & & \\
\hline
\end{tabular}

Figure 3. Assistive Technology Application Scenarios.

\subsection{Resources}

Even with all of the experiences we have attempted to facilitate via our AT Lab and various activities, we are aware that exposure to AT remains limited and is never complete given the rapid pace of new developments in the field of AT. Thus, we strive to provide students with resources they can refer to in the future when making AT determinations. The aforementioned QR codes posted around our lab are one way we accomplish this. Additionally, a list of some of the most helpful resources to provide students is provided in Figure 4. 


\section{Resources}

After experiencing the AT Lab, we realize you may wish to learn more. To help you on your journey we have developed a list of resources for you to use to help learn more.

Texas Technology Access Program:

https://tatp.edb.utexas.edu

A program to increase access to Assistive Technology for people with disabilities. The site provides resources for borrowing, recycling, and funding AT.

The Iris Center Module on AT:

https://iris.peabody.vanderbilt.edu/module/at/

The Iris Center is an organization with the goal of improving education outcomes for all children. The module listed here specifically covers the topic of AT.

National Center on Accessible Educational Materials:

http://aem.cast.org/navigating/assistive-technology-resources.html\#.WkLQBOaFNLM

The National Center on Accessible Educational Material provides resources for all on accessible educational materials. The above link provides a list of Assistive Technology resources.

\section{Reading Rockets:}

http://www.readingrockets.org/article/assistive-technology-kids-learning-disabilities-overview Reading Rockets is a nationwide multimedia literary initiative that provides information of how children learn to read and provide resources and information for adults to help those struggling. The site above provides an overview of different types of AT available and questions adults can ask to guide their decision-making.

\section{WrightsLaw:}

http://www.wrightslaw.com/info/atech.index.htm Wrights Law is an online resource that provides information on special education law, education law, and advocacy for students with disabilities. The link above provides legal information and additional resources pertaining to $A T$.

MaxiAIDS:

https://www.maxiaids.com/

This is a store that provides AT for daily living.

\section{Assistive Technology Industry Association}

https://www.atia.org/at-resources/what-is-at/

This organization is for manufacturers, sellers, and providers of AT. The link above provides a $n$ overview of AT and links to other resources. Additionally, the site features research on AT.

\section{Family Caregiver Alliance National Center on Caregiving}

https://www.caregiver.org/assistive-technology

This organization provides resources for caregivers. The link above discusses AT and provides resources for incorporating AT in the home. While many of these resources are geared towards older adults, some can be useful for people of all ages.

If you need additional resources or have additional questions about more specific concerns, reach out to us and we will work to find you the right resource.

Figure 4. Assistive Technology Resources.

\section{Lab Promotion}

Promoting the lab is an important piece of the equation, in order to make sure that the lab is utilized to its fullest extent. This has involved several components and is an on-going process. The first was a grand opening with the Dean of the College of Education and Human Services and the Provost of the University attending. The grand opening was held approximately one year after initial plans for 
the lab began, and involved a formal ribbon-cutting and viewing of the lab video detailed below. Press releases to announce the grand opening appeared in the school newspaper as well as a newspaper in the community. As part of this opening, a video was made of the ribbon-cutting and was posted to the AT Lab website [14]. Since its opening, the project lead updates the lab website as needed and sends out each semester's lab operation hours to each professor that has expressed an interest in the lab as a way of encouraging them to schedule a time to come visit the lab. This is intended to allow for the development of additional educational opportunities for students through effective planning and collaboration with their professors.

\section{Lab Video Orientation Tool}

When students enter the lab for the first time, they are shown a video that explains the purpose of the lab, its setup, and a brief introduction to some of the technology in the lab [9]. This video was developed by the campus center for faculty excellence and innovation (CFEI). The project lead edited a script prepared by CFEI, and the video was shot in the lab. The video depicts people interacting with lab materials, while showing the activity and lab from different angles. While this video is showing people interacting with the lab, a voice over the video describes each station, materials available in the lab, and the purpose of the lab. The video is an introduction for students to the overall organization to assist their exploration and learning, and it is published on the AT Lab website.

\section{Conclusions}

The vision and purpose for the creation of the AT Lab at TAMU-C is to support university efforts to provide pre-service teachers with exposure to and experiences with AT. Whether these teachers go on to work in general education or special education, this knowledge will arm them with the ability to make informed decisions regarding the consideration of AT during annual IEP meetings and help ensure the AT is implemented as intended. The AT Lab also provides a place for future research related to students' use of AT and methods for instructing pre-service teachers. It is our belief that AT is an essential component of any teacher preparation program, and the creation and utilization of an AT lab is one that will pay dividends for countless students.

Author Contributions: Beth A. Jones was the project lead in designing and setting up the lab. She worked with numerous departments to obtain the lab space, equipment, and set up the lab. Beth Jones was the primary author of this text and was instrumental in proofreading and revising. Nichole Williams currently serves as the part-time GA in the lab and has lead instruction in the lab. Nichole Williams drafted text, assisted with lab activity development, and created the figures. Belinda Rudinger assisted with lab set up, literature review, and editing.

Conflicts of Interest: The authors declare no conflict of interest.

\section{References}

1. U.S. Department of Education. 38th Annual Report to Congress on the Implementation of the Individuals with Disabilities Education Act. 2016. Available online: https://www2.ed.gov/about/reports/annual/ osep/2016/parts-b-c/38th-arc-for-idea.pdf (accessed on 29 November 2017).

2. Judge, S.; Simms, K. Assistive technology training at the pre-service level: A national snapshot of teacher preparation programs. Teach. Educ. Spec. Educ. 2009, 32, 33-44. [CrossRef]

3. Lee, Y.; Vega, L. Perceived knowledge, attitudes, and challenges of AT use in special education. J. Spec. Educ. Technol. 2017, 20, 60-63.

4. Conner, C.; Snell, M.; Gansneder, B.; Dexter, S. Special education teachers' use of assistive technology with students who have severe disabilities. J. Technol. Teach. Educ. 2017, 18, 369-386.

5. Bausch, M.; Ault, M. Status of Assistive Technology Instruction in University Personnel Preparation Programs. Assist. Technol. Outcomes Benefits 2012, 8, 1-14.

6. UT Austin Assistive and Instructional Technology Lab. Available online: https://www.facebook.com/UTAustin-Assistive-and-Instructional-Technology-Lab-1885640858333318/ (accessed on 29 November 2017). 
7. Esther's Place Virtual Tour-American Foundation for the Blind. Available online: http://www.afb. org/info/programs-and-services / center-on-vision-loss/what-we-do/esthers-place-virtual-tour/1234 (accessed on 4 October 2017).

8. UNC TEACCH Autism Program. Available online: https://www.teacch.com/ (accessed on 29 November 2017).

9. What Is TEACCH? Available online: http://www.autism-community.com/what-is-teacch/ (accessed on 26 December 2017).

10. Flower, A.; Burns, M.K.; Bottsford-Miller, N.A. Meta-analysis of disability simulation research. Rem. Spec. Educ. 2007, 2, 72-79. [CrossRef]

11. Bryant, D.P.; Erin, J.; Lock, R.; Allan, J.M.; Resta, P.E. Infusing a teacher preparation program in learning disabilities with assistive technology. J. Learn. Disabil. 1998, 31, 55-66. [CrossRef] [PubMed]

12. Zabala, J. The SETT Framework: Critical Areas to Consider When Making Informed Assistive Technology Decisions. Available online: http://dgmpresentations.pbworks.com/w/file/fetch/52424668/SETT\% 20description\%20and\%20forms.pdf (accessed on 26 December 2017).

13. Bowser, G.; Zabala, J. SETT and Re-SETT: Concepts for AT implementation. ConnSENSE Bull. 2005, 23, 1-4.

14. Assistive Technology Lab-Texas A\&M University-Commerce. Available online: http://www.tamuc.edu/ academics / colleges/educationHumanServices / departments / psychologyCounselingSpecialEducation/ special-education/at-lab/default.aspx (accessed on 29 November 2017).

(C) 2018 by the authors. Licensee MDPI, Basel, Switzerland. This article is an open access article distributed under the terms and conditions of the Creative Commons Attribution (CC BY) license (http://creativecommons.org/licenses/by/4.0/). 